Article

\title{
Ectopic eye tooth management: Photobiomodulation / low-level laser emission role in root resorption after fixed Orthodontic treatment.
}

\author{
Mohammad Khursheed Alam ${ }^{1 *}$, Kiran Kumar Ganji ${ }^{2 \sharp}$, Ahmed Ali Alfawzan ${ }^{3}$, Srinivas Munisekhar Manay ${ }^{2}$, \\ Kumar Chandan Srivastava ${ }^{4}$, Prabhat Kumar Chaudhari 5, Hala A. Hosni ${ }^{4}$, Haytham Jamil Alswairki ${ }^{6}$, and Reem \\ Alansari 7
}

1 Professor, Orthodontics, Preventive Dentistry Department, College of Dentistry, Jouf University, Saudi Arabia; mkalam@ju.edu.sa \& dralam@gmail.com (MKA).

2 Preventive Dentistry Department, College of Dentistry, Jouf University, Saudi Arabia; kiranperio@gmail.com; dr.srinivas.manay@jodent.org

3 Department of Preventive Dentistry, College of Dentistry in Ar Rass, Qassim University, Ar Rass, Saudi Arabia; dr.ahmed.alfawzan@qudent.org

4 Department of Oral Surgery and Radiology, College of Dentistry, Jouf University, Saudi Arabia; dr.kumar.srivastava@jodent.org; dr.hala.hosni@jodent.org

5 Division of Orthodontics and Dentofacial Deformities, Centre for Dental Education and Research, All India Institute of Medical Sciences, New Delhi-110029, India.; dr.prabhatkc@gmail.com

6 School of Dental Sciences, Universiti Sains Malaysia. Kota Bharu 16150, Kelantan, Malaysia. hitham.swerki@gmail.com

7 Orthodontic Department, King Abdulaziz University, Jeddah, Saudi Arabia. ralansari@kau.edu.sa

* Correspondence: mkalam@ju.edu.sa \& dralam@gmail.com

\# Mohammad Khursheed Alam and Kiran Kumar Ganji contributed equally and both are the $1^{\text {st }}$ author.

\begin{abstract}
The orthodontic treatment brings numerous benefits and, in most cases, the benefits outweigh the possible disadvantages. Root resorption (RR) is a common adverse phenomenon associated with orthodontic treatment. This study evaluates the role of low-level laser emission / Photobiomodulation (LE/P) in quantitative measurements of root resorption (QRR). The application of LE/P done after each orthodontic activation with 4 types of treatment intervention (TI) on the RR after fixed orthodontic treatment (FOT) of the upper arch with ectopic eye tooth/teeth [EET]. 32 Orthodontic patients scheduled for FOT were selected and assigned to the 4 groups. These were LE/P+Self ligating bracket (SLB), LE/P+Conventional bracket (CB), Non-Photobiomodulation (non-LE/P)+SLB and non-LE/P+CB. Standard management stages of FOT were followed in the maxilla. Each patient received a single application of LE/P labially/buccally and palatally, a total of 5 different points during each activation or appointment. The main outcome measure was QRR in maxillary anteriors before and after FOT assessed via cone-beam computed tomography (CBCT) using 3D OnDemand software. Insignificant $Q R R$ was found between before and after FOT in SLB, $\mathrm{CLB}$, and LE/P, non-LE/P groups ( $\mathrm{p}>0.05)$. QRR in the SLB vs CB and LE/P vs non-LE/P group was significantly different in 11,13 , and $23(\mathrm{p}<0.05)$. QRR in the LE/P+SLB group $(\mathrm{p}<0.05)$ was significantly different in 11, 13, and 23 than that in the other groups. The most severe QRR was found on the $13(0.88 \pm 0.28 \mathrm{~mm}$ and $0.87 \pm 0.27 \mathrm{~mm})$ and $23(1.19 \pm 0.14 \mathrm{~mm}$ and $1.16 \pm 0.13 \mathrm{~mm})$ in the $C B$ and non-LE/P group $(\mathrm{p}<0.001)$. LE/P+SLB showed highly significant superior outcome $(\mathrm{p}<0.001)$ in relation to non- $\mathrm{LE} / \mathrm{P}+\mathrm{CB}$, the $\mathrm{QRR}$ of 23 were $0.813 \pm 0.114 \mathrm{~mm}$ and $1.156 \pm 0.166 \mathrm{~mm}$ respectively. Significantly higher amount of QRR found in EET patients after FOT treated with the $C B$, non-LE/P, and non-LE/P+CB system and warrants further investigation to explore potential specific causes.
\end{abstract}

Keywords: Photobiomodulation; low level laser therapy; ectopic eye tooth; root resorption; treatment modalities. 


\section{Introduction}

Primary concern of any orthodontic management is the improvement of dental and facial aesthetics rather than the other oral health benefits in patient [1, 2]. Every intervention has menace or impediments, fixed orthodontic treatment (FOT) is not free from adverse effects. For Orthodontic tooth movement (OTM), the unbalanced force might result in detrimental treatment consequences like root resorption (RR), pain, overdue tooth movement, loss of vitality of the tooth [3]. Different studies established that OTM is a complex phenomenon and involves loss of the alveolar bone or tooth root $[4,5]$.

Malocclusion is a typical marvel which could be seen in a large portion of the individuals around the globe. Malocclusion considered as off base connection between and among the malalignment of the teeth of the both arches $[1,6,7]$. This condition as a rule could be perceived at an early age and bit by bit shows with development which powers a person to look for an FOT.

An ectopic eye tooth (EET) is a maxillary canine which follows deviant route of eruption. Due to such barrier EET can be impacted or blocked from erupting or displaced buccally or palatally. Regardless of advancement in the field of Orthodontics, fruitful management of EET still represents a challenge to the clinicians. They are normally guided to appropriate arrangement in the dental arch by surgical exposure followed by orthodontic traction [8].

$\mathrm{RR}$ is one of the most widely recognized unfavorable impacts of a wide range of orthodontic treatments which may begin in any phase of the treatment, for example, starting, retraction, alignment and completing stage. RR may initiate around 2-5 weeks of activation, and it requires 3-4 such activations to be recognized in radiographs [9]. Albeit numerous parts of this unfortunate impact stay hazy, it is a perplexing natural procedure, happened when the orthodontic activation at the root apex region surpasses the opposition and reparative fitness of the periapical tissues [10]. The hereditary impact is most significant attributed factors credited to the RR during orthodontic management [11]. Photobiomodulation (LE/P) has promising advantages on OTM [12-16], pain management [13, 15, 17-19] and gingival tissue and periodontal tissue [20]. It has been uncovered that LE/P essentially increment osteoblast cells during their expansion and separation stages. In this manner, prompts bone renovating by invigorating osteogenesis [21-24]. Quality bone recovery prompts the better bone redesigning which is basic for OTM. Till to date based on literature search no study has been found which assessed the QRR associated with LE/P in FOT. Hence, the general research objectives was to explore QRR via 3D CBCT after FOT in the patients undergoing fixed orthodontic treatment of maxillary arch with ectopically erupted canines. Specifically, Compare the QRR -

1. in two-treatment modalities namely self-ligating bracket (SLB) vs conventional bracket $(\mathrm{CB})$.

2. in two-treatment intervention (TI) [LE/P vs non-LE/P].

3. in four different TI (LE/P+SLB, LE/P+CB, non-LE/P+SLB, and non-LE/P+CB).

4. in three different phenotypes of EET (Unilateral 13, Unilateral 23 and Bilateral)

5. in three different phenotype positions of EET (Buccal, Occlusal and Palatal)

\section{Hypotheses}

There was a significant difference in the QRR in different types of fixed appliances, different treatment interventions and different phenotype of ectopically erupted canines.

\section{Research Question}

In the patients undergoing FOT of maxillary arch with EET (unilateral or bilateral) with different phenotype positions (buccal, occlusal, palatal) using SLB and CB system, what is the effect of LE/P intervention as compared to control on the QRR?

\section{Materials and Methods}


Thirty-two (32) patients were enrolled were further subdividing into two groups based upon the two different types of orthodontic appliances used i.e. SLB and CB. These two groups were further subdivided into two subgroups based upon the TI using LE/P. The different study groups have been presented in the Figure 1.
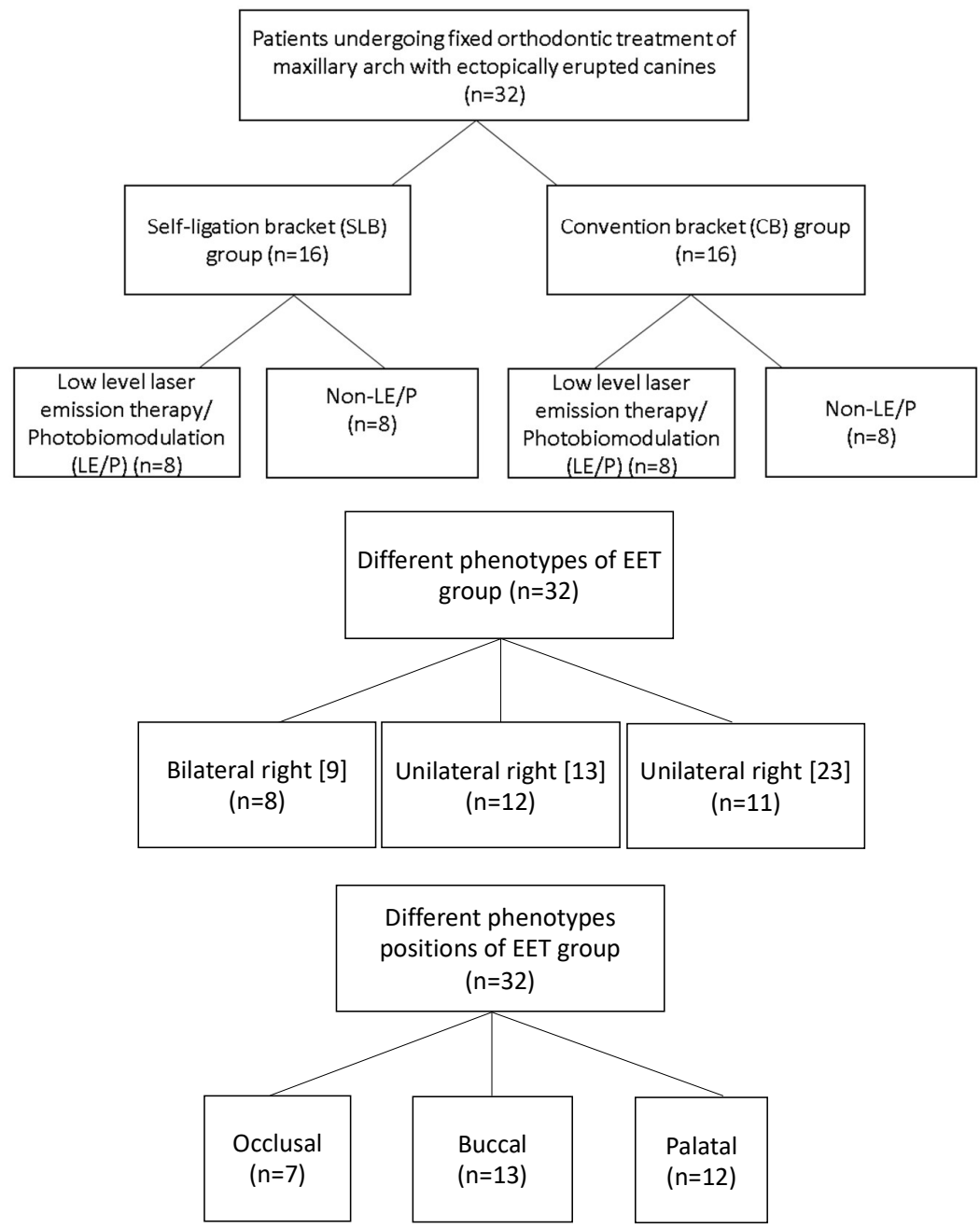

Figure 1: Showing different groups of study population

The details of inclusion, exclusion, sample size calculation, LE/P (13, 15, 16-19), FOT, methods of the QRR measurements outcome (25) and the reliability are present in Figure 2. CBCT were taken during initial record (Pre) and the day of debonding (Post FOT) are used for the RR outcome measurements. Average duration of FOT were 19.40 and 20.63 months in the SLB and CB group respectively.

\section{Statistical analysis}

Paired t-test, independent t-test and ANOVA with post-hoc Tukey tests are used for testing the comparisons in groups. SPSS version 26 (Chicago IL, USA) used for the analysis.

\section{Results}


The average age of the patients was $19.5( \pm 1.5)$ with 18 males and 14 females. A paired-sample t-test was conducted to evaluate the impact of the SLB and CB on the level of QRR after FOT. The results showed an insignificant ( $p>0.05)$ QRR in both the groups (Table 1). The mean increase in QRR was highest in \#23 of both the techniques SLB and $\mathrm{CB}$ with a $95 \% \mathrm{CI}$ ranging from $\mathbf{0 . 9 4}$ to 1.19 . The effect size static (0.97) was highest in relation to $\# 23$ of $C B$ group.

The results of independent t-test performed for the mean QRR (\#11, \#12, \#21, \#22, \#13 and $\# 23)$ in SLB vs CB groups revealed statistically significant disparities only in \#11, \#13 and \#23 ( $\mathrm{p}<0.05)$ (Figure 3).

A paired-samples t-test was conducted to evaluate the impact of the LE/P and non-LE/P on the level of QRR. The results showed an insignificant ( $p>0.05)$ QRR in both the groups after FOT (Table 2). The mean increase in QRR was highest in \#23 of both the techniques LE/P and non-LE/P with a 95\% CI ranging from 0.93 to 1.16 . The effect size static (0.92) was highest in relation to $\# 23$ of non-LE/P indicating high rate of resorption in non-LE/P group.

The results of independent t-test performed for the mean QRR (\#11, \#12,\#21, \#22, \#13 and $\# 23$ ) in LE/P and non-LE/P groups revealed that statistically significant disparities in \#11, $\# 13$ and $\# 23$ ( $\mathrm{p}<0.05)$ (Figure 4 ).

The type of technique (LE/P and non-LE/P) and type of brackets (SLB/CB) had a significant impact on the resorption levels in \#11 (F=3.830), \#13 (F=1.770) and \#23 (F=15.521) $\mathrm{p}<0.05$ respectively (Table 3 ).

The Graph 3 revealed that there was a significant difference between the mean resorption levels of \#11 in LE/P+SLB and LE/P+CB with that of non-LE/P+CB. With respect to \#13 there was significant difference between the mean resorption levels in LE/P+SLB and non-LE/P+SLB with that of non-LE/P+CB whereas in case of $\# 23$ significant difference was found in $\mathrm{LE} / \mathrm{P}+\mathrm{SLB}$ with that of non-LE/P+SLB, LE/P+CB and non-LE/P+CB.

The ectopic canine pattern and canine position didn't show any significant impact on the resorption levels of \#11,\#21, \#12,\#22, \#13 and \#23 (Table 4 ,Table 5 \& Figure 5). 


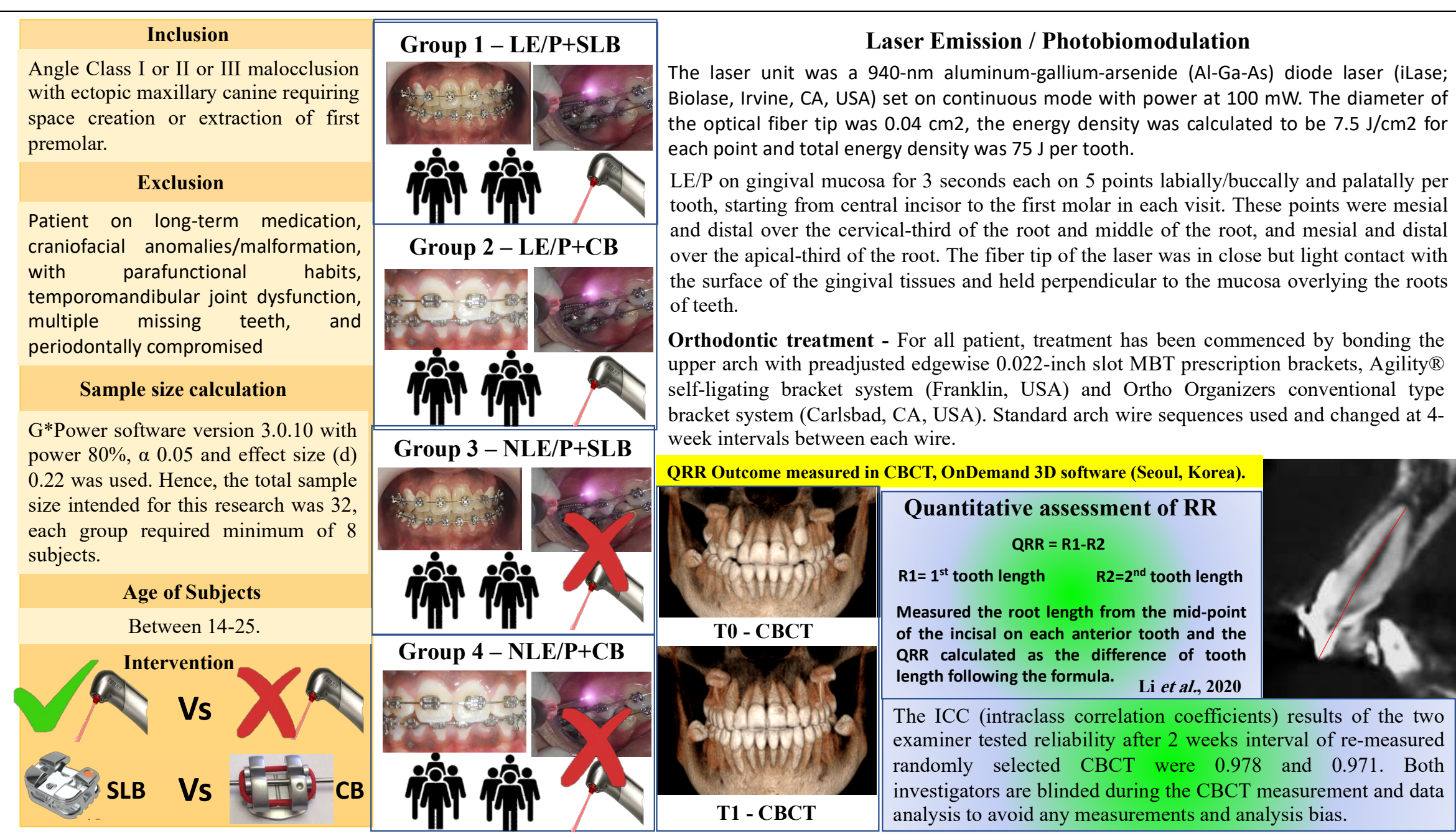

Figure 1. Details of the methodology 
Table 1: Mean comparison of root resorption after orthodontic therapy in SLB and CB group

\begin{tabular}{|c|c|c|c|c|c|c|c|}
\hline \multirow{2}{*}{$\begin{array}{c}\text { Root length } \\
\text { comparison } \\
\text { before }(\mathrm{R} 1) \text { and } \\
\text { after }(\mathrm{R} 2) \\
\text { orthodontic } \\
\text { treatment } \\
\end{array}$} & \multirow{2}{*}{ Group } & \multirow{2}{*}{$\mathbf{N}$} & \multirow{2}{*}{$\begin{array}{c}\text { Mean } \\
\text { Root } \\
\text { resorption } \\
\text { R= (R2-R1) } \\
\text { mm }\end{array}$} & \multicolumn{3}{|c|}{$\begin{array}{l}\text { 95\% Confidence } \\
\text { Interval of the } \\
\text { Difference }\end{array}$} & \multirow{2}{*}{ t-value } \\
\hline & & & & & Lower & Upper & \\
\hline \multirow{2}{*}{$11 \mathrm{R} 1-11 \mathrm{R} 2$} & SLB & 16 & 0.29 & 0.18 & 0.19988 & 0.39262 & \multirow{2}{*}{2.02} \\
\hline & $\mathrm{CB}$ & 16 & 0.20 & 0.04 & 0.18389 & 0.22236 & \\
\hline \multirow{2}{*}{$21 R 1-21 R 2$} & SLB & 16 & 0.23 & 0.08 & 0.18226 & 0.27274 & \multirow{2}{*}{-0.21} \\
\hline & $\mathrm{CB}$ & 16 & 0.23 & 0.06 & 0.19955 & 0.26670 & \\
\hline \multirow{2}{*}{$12 \mathrm{R} 1-12 \mathrm{R} 2$} & SLB & 16 & 0.18 & 0.23 & 0.05793 & 0.30332 & \multirow{2}{*}{0.08} \\
\hline & $\mathrm{CB}$ & 16 & 0.18 & 0.07 & 0.13628 & 0.21497 & \\
\hline \multirow{2}{*}{$22 \mathrm{R} 1-22 \mathrm{R} 2$} & SLB & 16 & 0.29 & 0.04 & 0.26827 & 0.31548 & \multirow{2}{*}{0.71} \\
\hline & $\mathrm{CB}$ & 16 & 0.28 & 0.07 & 0.23916 & 0.31459 & \\
\hline \multirow{2}{*}{$13 R 1-13 R 2$} & SLB & 16 & 0.57 & 0.13 & 0.50228 & 0.64147 & \multirow{2}{*}{$-.3 .91$} \\
\hline & $\mathrm{CB}$ & 16 & 0.88 & 0.28 & 0.72614 & 1.02886 & \\
\hline \multirow{2}{*}{ 23R1 - 23R2 } & SLB & 16 & 0.94 & 0.17 & 0.84683 & 1.03067 & \multirow{2}{*}{-4.51} \\
\hline & $\mathrm{CB}$ & 16 & 1.19 & 0.14 & 1.11499 & 1.26376 & \\
\hline
\end{tabular}

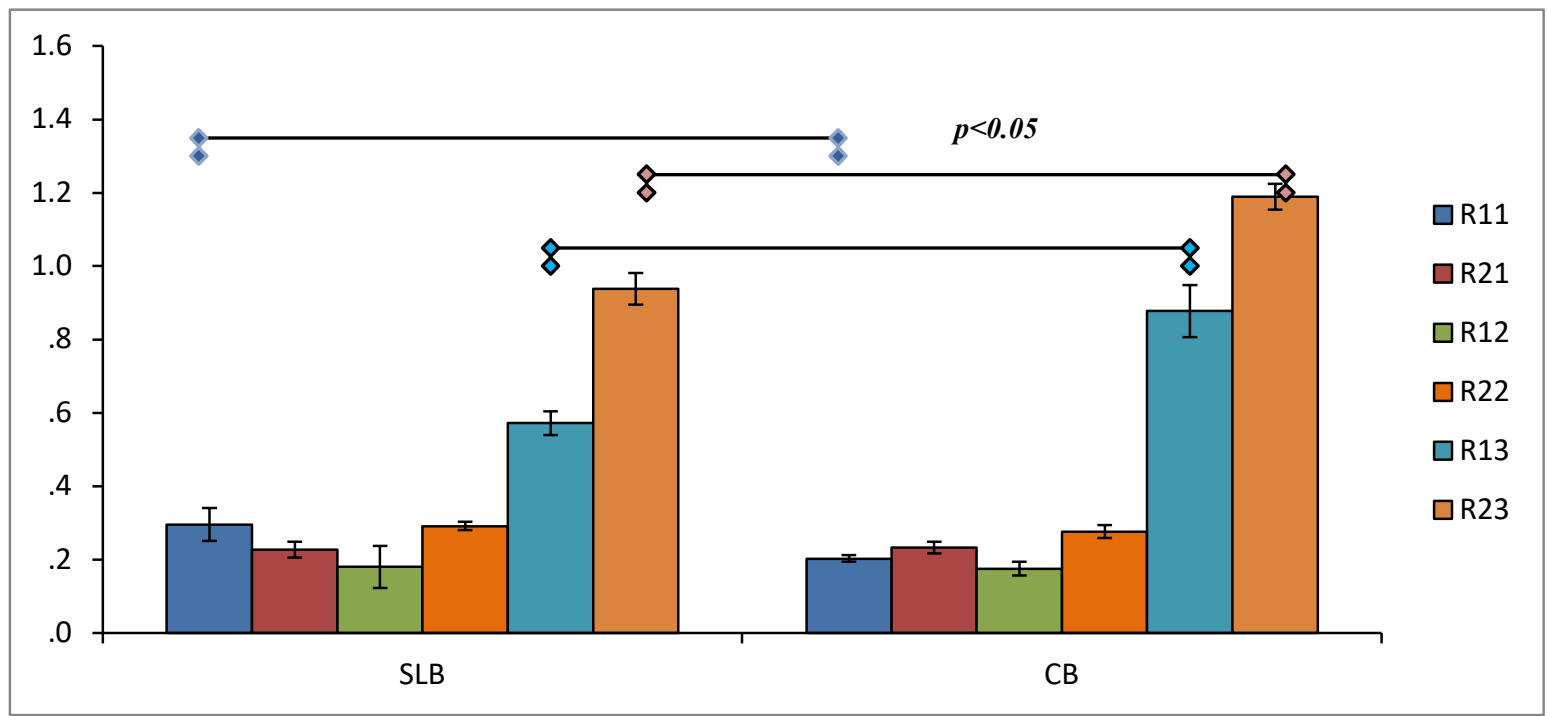

Figure 3: Graphical representation of significance difference in root resorption within intra-group comparison of SLB \& CB

Table 2: Mean comparison of root resorption after orthodontic therapy in Laser and Non-laser group 


\begin{tabular}{|c|c|c|c|c|c|c|c|}
\hline \multirow{2}{*}{$\begin{array}{c}\text { Root length } \\
\text { comparison before } \\
\text { (R1) and after (R2) } \\
\text { orthodontic } \\
\text { treatment }\end{array}$} & \multirow[t]{2}{*}{ Group } & \multirow[t]{2}{*}{$\mathbf{N}$} & \multirow{2}{*}{$\begin{array}{c}\text { Mean } \\
\text { Root } \\
\text { resorption } \\
\mathbf{R =}=(\mathbf{R 2}-\mathbf{R} 1) \\
\mathbf{m m}\end{array}$} & \multirow{2}{*}{$\begin{array}{c}\text { Std. } \\
\text { Deviation }\end{array}$} & \multicolumn{2}{|c|}{$\begin{array}{c}95 \% \text { Confidence } \\
\text { Interval of the } \\
\text { Difference } \\
\end{array}$} & \multirow[t]{2}{*}{ t-value } \\
\hline & & & & & Lower & Upper & \\
\hline \multirow{2}{*}{$11 \mathrm{R} 1-11 \mathrm{R} 2$} & $\mathrm{LE} / \mathrm{P}$ & 16 & 0.30 & 0.08 & 0.01830 & 0.10920 & \multirow{2}{*}{0.28} \\
\hline & Non-LE/P & 16 & 0.22 & 0.05 & 0.01797 & 0.10953 & \\
\hline \multirow{2}{*}{ 21R1 - 21R2 } & LE/P & 16 & 0.23 & 0.07 & -0.03820 & 0.05195 & \multirow{2}{*}{0.31} \\
\hline & Non-LE/P & 16 & 0.23 & 0.05 & -0.03833 & 0.05208 & \\
\hline \multirow{2}{*}{$12 \mathrm{R} 1-12 \mathrm{R} 2$} & $\mathrm{LE} / \mathrm{P}$ & 16 & 0.23 & 0.18 & -0.06414 & 0.12539 & \multirow{2}{*}{0.66} \\
\hline & Non-LE/P & 16 & 0.19 & 0.06 & -0.06681 & 0.12806 & \\
\hline \multirow{2}{*}{$22 \mathrm{R} 1-22 \mathrm{R} 2$} & $\mathrm{LE} / \mathrm{P}$ & 16 & 0.27 & 0.05 & -0.03439 & 0.03814 & \multirow{2}{*}{0.10} \\
\hline & Non-LE/P & 16 & 0.27 & 0.05 & -0.03439 & 0.03814 & \\
\hline \multirow{2}{*}{ 13R1 - 13R2 } & $\mathrm{LE} / \mathrm{P}$ & 16 & 0.56 & 0.12 & -0.46058 & -0.15692 & \multirow{2}{*}{-4.15} \\
\hline & Non-LE/P & 16 & 0.87 & 0.27 & -0.46331 & -0.15419 & \\
\hline \multirow{2}{*}{$23 R 1-23 R 2$} & LE/P & 16 & 0.93 & 0.17 & -0.33628 & -0.11497 & \multirow{2}{*}{-4.16} \\
\hline & Non-LE/P & 16 & 1.16 & 0.13 & -0.33653 & -0.11472 & \\
\hline
\end{tabular}

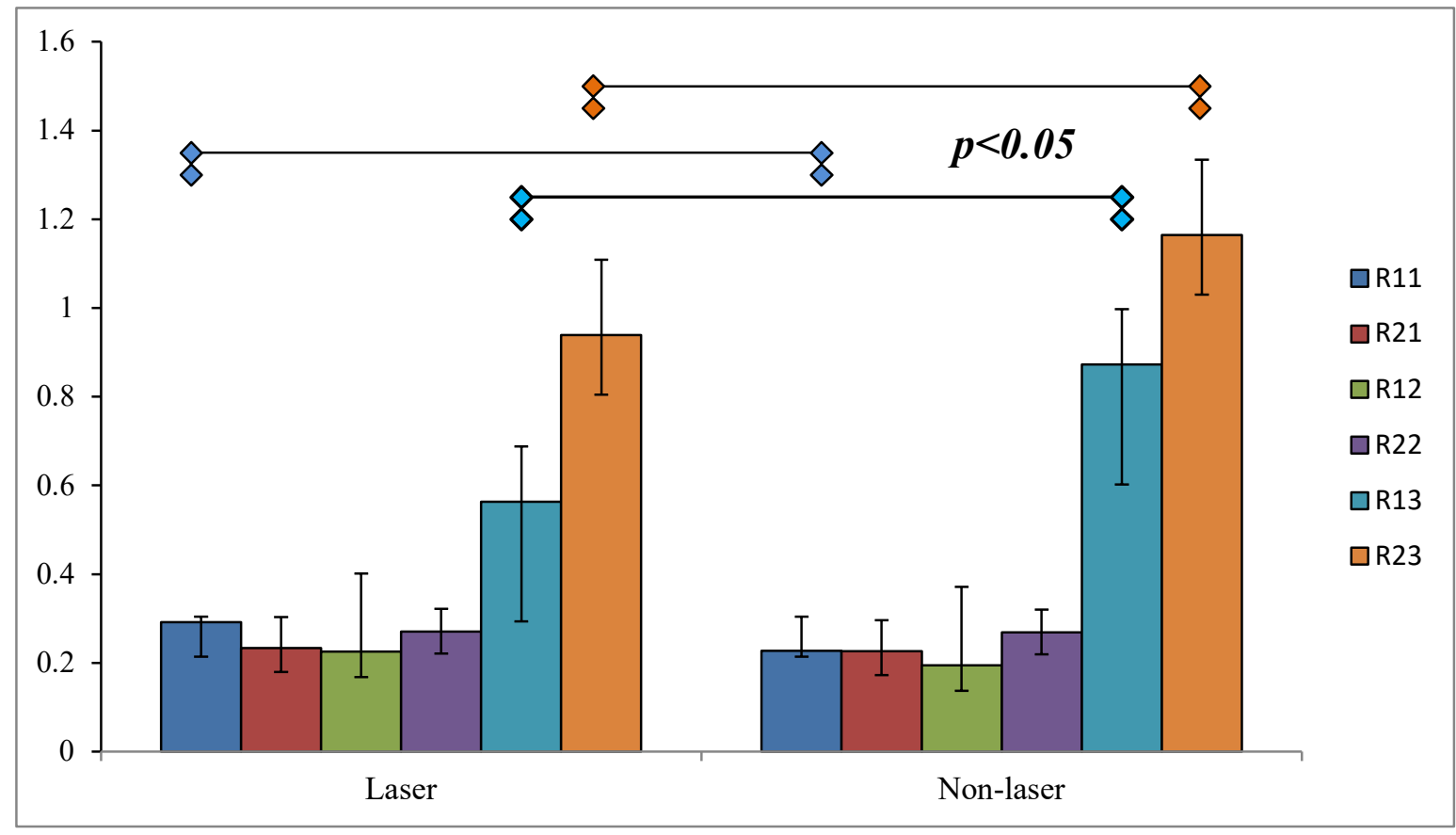

Figure 4: Graphical representation of significance difference in root resorption within intra-group comparison of Laser \& Non-laser group 
Table 3: ANOVA test results of mean root resorption $(R)$ for the measured tooth (\#11, \#21, \#12, \#22, \#13, \#23) within Laser SLB, Non Laser SLB, Laser CB and Non laser CB group

\begin{tabular}{|c|c|c|c|c|c|c|}
\hline Tooth & Groups & $\mathbf{N}(32)$ & $\begin{array}{c}\text { Mean } \\
\text { Resorption (R) }\end{array}$ & Std. Deviation & F value & $p$ value \\
\hline \multirow{4}{*}{11} & $\mathrm{LE} / \mathrm{P}+\mathrm{SLB}$ & 8 & 0.3750 & 0.22960 & \multirow{4}{*}{3.830} & \multirow{4}{*}{$0.020^{*}$} \\
\hline & Non-LE/P+SLB & 8 & 0.2175 & 0.05651 & & \\
\hline & $\mathrm{LE} / \mathrm{P}+\mathrm{CB}$ & 8 & 0.2038 & 0.04955 & & \\
\hline & Non-LE/P+CB & 8 & 0.2025 & 0.01832 & & \\
\hline \multirow{4}{*}{21} & $\mathrm{LE} / \mathrm{P}+\mathrm{SLB}$ & 8 & 0.2137 & 0.06523 & \multirow{4}{*}{0.204} & \multirow{4}{*}{0.893} \\
\hline & Non-LE/P+SLB & 8 & 0.2413 & 0.10371 & & \\
\hline & $\mathrm{LE} / \mathrm{P}+\mathrm{CB}$ & 8 & 0.2375 & 0.05548 & & \\
\hline & Non-LE/P+CB & 8 & 0.2287 & 0.07338 & & \\
\hline \multirow{4}{*}{12} & $\mathrm{LE} / \mathrm{P}+\mathrm{SLB}$ & 8 & 0.2075 & 0.25645 & \multirow{4}{*}{0.323} & \multirow{4}{*}{0.809} \\
\hline & Non-LE/P+SLB & 8 & 0.1537 & 0.21494 & & \\
\hline & $\mathrm{LE} / \mathrm{P}+\mathrm{CB}$ & 8 & 0.1425 & 0.07086 & & \\
\hline & Non-LE/P+CB & 8 & 0.2088 & 0.06446 & & \\
\hline \multirow{4}{*}{22} & LE/P+SLB & 8 & 0.2612 & 0.03563 & \multirow{4}{*}{1.770} & \multirow{4}{*}{0.176} \\
\hline & Non-LE/P+SLB & 8 & 0.3225 & 0.02816 & & \\
\hline & $\mathrm{LE} / \mathrm{P}+\mathrm{CB}$ & 8 & 0.2738 & 0.09164 & & \\
\hline & Non-LE/P+CB & 8 & 0.2800 & 0.04811 & & \\
\hline \multirow{4}{*}{13} & LE/P+SLB & 8 & 0.5900 & 0.09118 & \multirow{4}{*}{5.076} & \multirow{4}{*}{$0.006^{*}$} \\
\hline & Non-LE/P+SLB & 8 & 0.5537 & 0.16578 & & \\
\hline & $\mathrm{LE} / \mathrm{P}+\mathrm{CB}$ & 8 & 0.8362 & 0.27412 & & \\
\hline & Non-LE/P+CB & 8 & 0.9187 & 0.30638 & & \\
\hline \multirow{4}{*}{23} & LE/P+SLB & 8 & 0.8125 & 0.11449 & \multirow{4}{*}{15.521} & \multirow{4}{*}{$0.000 *$} \\
\hline & Non-LE/P+SLB & 8 & 1.0650 & 0.11928 & & \\
\hline & $\mathrm{LE} / \mathrm{P}+\mathrm{CB}$ & 8 & 1.2225 & 0.10859 & & \\
\hline & Non-LE/P+CB & 8 & 1.1563 & 0.16570 & & \\
\hline
\end{tabular}




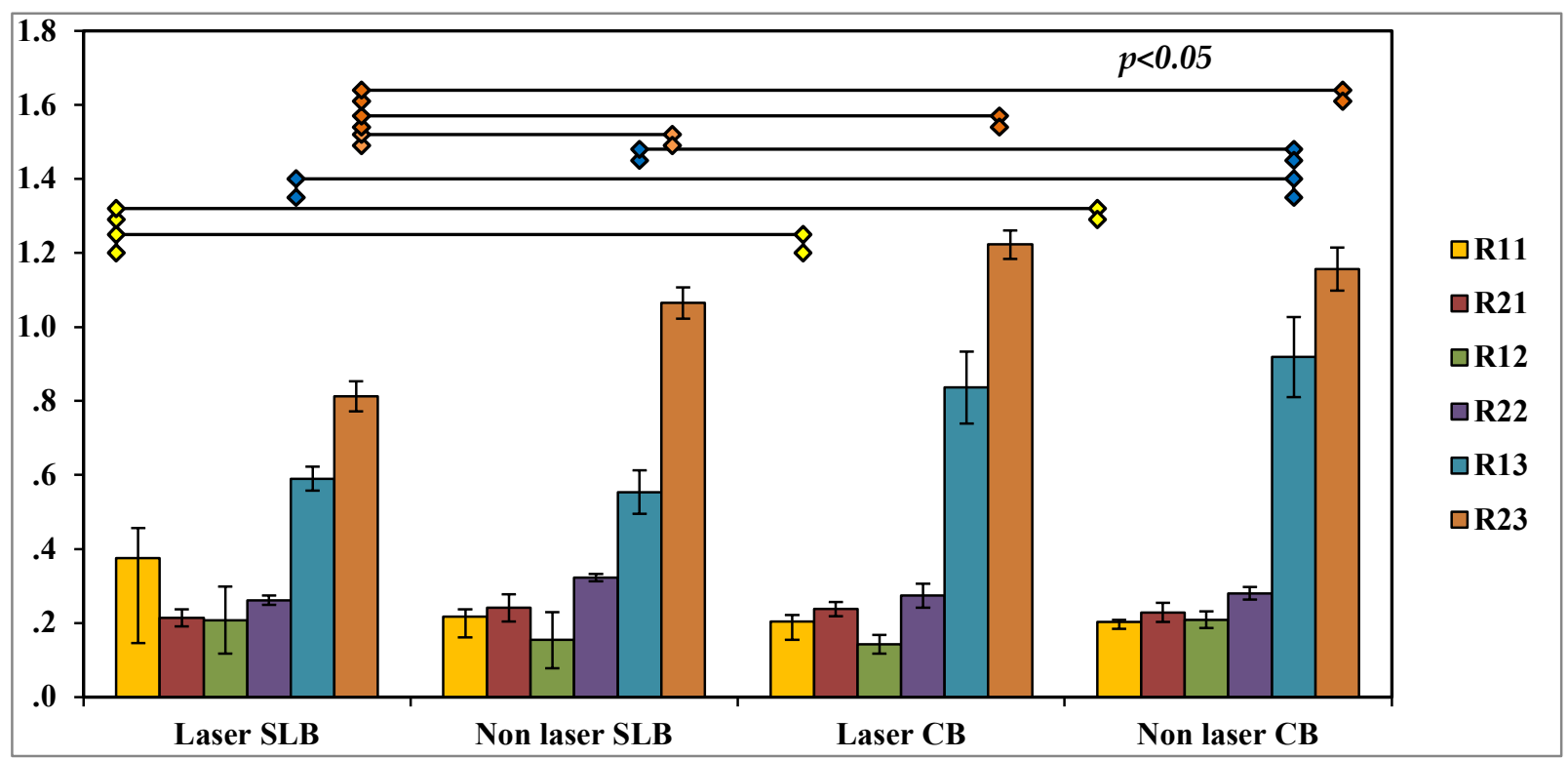

Figure 5: Graphical representation of Tukey's Post-hoc test results for intra-group significance

Table 4: ANOVA test results of mean root resorption $(\mathrm{R})$ for the measured tooth (\#11, \#21, \#12, \#22, \#13, \#23) within bilateral, Unilateral 13, Unilateral 23 ectopic canine groups

\begin{tabular}{|c|c|c|c|c|c|c|}
\hline Tooth & Ectopic canine & $\mathbf{N}(32)$ & Mean & Std. Deviation & F value & $p$ value \\
\hline \multirow{3}{*}{11} & Bilateral & 9 & 0.1989 & 0.04343 & \multirow{3}{*}{1.703} & \multirow{3}{*}{0.200} \\
\hline & Unilateral 13 & 12 & 0.3033 & 0.20299 & & \\
\hline & Unilateral 23 & 11 & 0.2327 & 0.07086 & & \\
\hline \multirow{3}{*}{21} & Bilateral & 9 & 0.2278 & 0.07259 & \multirow{3}{*}{0.007} & \multirow{3}{*}{0.993} \\
\hline & Unilateral 13 & 12 & 0.2308 & 0.04522 & & \\
\hline & Unilateral 23 & 11 & 0.2318 & 0.10157 & & \\
\hline \multirow{3}{*}{12} & Bilateral & 9 & 0.2322 & 0.21730 & \multirow{3}{*}{0.636} & \multirow{3}{*}{0.536} \\
\hline & Unilateral 13 & 12 & 0.1600 & 0.12649 & & \\
\hline & Unilateral 23 & 11 & 0.1536 & 0.16931 & & \\
\hline \multirow{3}{*}{22} & Bilateral & 9 & 0.2878 & 0.03701 & \multirow{3}{*}{1.002} & \multirow{3}{*}{0.380} \\
\hline & Unilateral 13 & 12 & 0.2667 & 0.05228 & & \\
\hline & Unilateral 23 & 11 & 0.3009 & 0.07648 & & \\
\hline \multirow{3}{*}{13} & Bilateral & 9 & 0.6200 & 0.30749 & \multirow{3}{*}{0.975} & \multirow{3}{*}{0.389} \\
\hline & Unilateral 13 & 12 & 0.7750 & 0.29950 & & \\
\hline & Unilateral 23 & 11 & 0.7555 & 0.18190 & & \\
\hline \multirow{3}{*}{23} & Bilateral & 9 & 1.0511 & 0.18937 & \multirow{3}{*}{0.236} & \multirow{3}{*}{0.791} \\
\hline & Unilateral 13 & 12 & 1.0425 & 0.18582 & & \\
\hline & Unilateral 23 & 11 & 1.0982 & 0.23549 & & \\
\hline
\end{tabular}


Table 5: ANOVA test results of mean root resorption for the measured tooth $\# 11, \# 21, \# 12, \# 22, \# 13$, \#23) within occlusal, buccal, palatal canine position groups

\begin{tabular}{|c|c|c|c|c|c|c|}
\hline Tooth & Canine position & $\mathbf{N}(32)$ & Mean & Std. Deviation & F value & $p$ value \\
\hline \multirow{3}{*}{11} & Occlusal & 7 & 0.2600 & 0.07000 & \multirow{3}{*}{0.964} & \multirow{3}{*}{0.393} \\
\hline & Buccal & 13 & 0.2108 & 0.03883 & & \\
\hline & Palatal & 12 & 0.2858 & 0.21232 & & \\
\hline \multirow{3}{*}{21} & Occlusal & 7 & 0.2500 & 0.07047 & \multirow{3}{*}{0.346} & \multirow{3}{*}{0.710} \\
\hline & Buccal & 13 & 0.2208 & 0.06551 & & \\
\hline & Palatal & 12 & 0.2292 & 0.08670 & & \\
\hline \multirow{3}{*}{12} & Occlusal & 7 & 0.1986 & 0.19239 & \multirow{3}{*}{0.158} & \multirow{3}{*}{0.855} \\
\hline & Buccal & 13 & 0.1869 & 0.14338 & & \\
\hline & Palatal & 12 & 0.1567 & 0.19047 & & \\
\hline \multirow{3}{*}{22} & Occlusal & 7 & 0.2657 & 0.04467 & \multirow{3}{*}{1.095} & \multirow{3}{*}{0.348} \\
\hline & Buccal & 13 & 0.2769 & 0.06316 & & \\
\hline & Palatal & 12 & 0.3033 & 0.05959 & & \\
\hline \multirow{3}{*}{13} & Occlusal & 7 & 0.6243 & 0.19139 & \multirow{3}{*}{0.772} & \multirow{3}{*}{0.472} \\
\hline & Buccal & 13 & 0.7246 & 0.24939 & & \\
\hline & Palatal & 12 & 0.7833 & 0.32129 & & \\
\hline \multirow{3}{*}{23} & Occlusal & 7 & 1.1286 & 0.21575 & \multirow{3}{*}{0.621} & \multirow{3}{*}{0.545} \\
\hline & Buccal & 13 & 1.0685 & 0.18920 & & \\
\hline & Palatal & 12 & 1.0217 & 0.20919 & & \\
\hline
\end{tabular}

\section{Discussion}

RR negatively affects patients' quality of life and treatment result during FOT. LE/P uses are popular in FOT and has been successfully tested in animal [12, 21-24] and human studies among the pain management [13, 15, 17-19] and acceleration of OTM [12-16] are common. However, QRR during the FOT using LE/P is yet to explored. Current study explored and compared the QRR in FOT patients treated with different TM (two groupings), TI (two and four groupings) and different phenotype factors (two different three groupings) of EET using CBCT, and found significant differences.

Treatment of EET is a costly, tedious procedure by fixed braces requires measure of time contingent on the case to adjust them inside the dental arch [8]. The orthodontic sections can be then clung to the uncovered canines (in case of impacted) and adjust them [8]. RR is where the loss of dental hard tissues is happening because of the clastic action of bone [26]. This marvel may likewise result as an obsessive or physiological procedure. Be that as it may, RR is considered as an ordinary physiological procedure in deciduous teeth except if it happens prematurely [27]. Numerous examinations have shown that RR is unequivocally affected by several environmental factors. Different mechanical variables 
may likewise include in RR during FOT, for example, rotation, supraocclussion, root tipping and infraocclusion etc. These relevant factors generally used during the OTM stage or completing phase of FOT which may exaggerated the formation of RR. Consequently, to recognize the treatment variety impacts and mechanical consequences for RR ought to be directed at a phase during FOT. Maybe, toward the finish of FOT, a system that led to progressing the RR, for example, the use of excessive force mechanics.

To investigate RR outcome, cephalogram, panoramic and, peri-apical radiographs were common using different techniques of measurement [28-30]. Present research used CBCT images to measure QRR outcome. CBCT images having high level of reproducibility and confirms its usage in FOT [31, 32]. Alqerban et al. (2009), Leite et al. (2012) and Li et al. (2020) also used the CBCT for the QRR outcome measurements [31, 33, 25]. The outputs created by a CBCT imaging framework with an altogether decreased sweep time diminished expense for the patient, and utilize a lower radiation portion than computed tomography (CT) [34].

Several investigation advocates SLB vs CB uses in FOT $[33,35,36]$ with the insignificant QRR outcome. Most of them investigates the outcome in the maxillary arch or in incisors teeth only. Current study assessed all anterior teeth of maxilla in a prospective study design others were controlled clinical trial or cohort study. Li et al. (2020) analysed the prevalence and severity of QRR in the clear aligners and FOT group were statistically and clinically significant [25]. Treatment groupings are completely different. In relation with FOT (average $1.12 \pm 1.34 \mathrm{~mm}$ ), the clear aligners (average $0.13 \pm 0.47 \mathrm{~mm}$ ) used in relatively simpler cases where QRR in all anterior tooth were significantly less. In FOT group, Li et al. (2020) found QRR differences (before and after) in maxillary central incisor $(1.23 \pm 1.31 \mathrm{~mm})$, lateral incisor $(1.31 \pm 1.33 \mathrm{~mm})$ and canine $(1.53 \pm 1.92 \mathrm{~mm})(25)$. In the current study FOT using CB show the QRR differences in $11(0.203 \mathrm{~mm}), 21(0.233 \mathrm{~mm}), 12$ (0.176), $22(0.277 \mathrm{~mm}), 13(0.878 \mathrm{~mm}), 23(1.189 \mathrm{~mm})$, and SLB show $11(0.296 \mathrm{~mm}), 21$ $(0.228 \mathrm{~mm}), 12(0.181), 22(0.292 \mathrm{~mm}), 13(0.572 \mathrm{~mm}), 23(0.939 \mathrm{~mm})$. In comparison to TM, 11,13 and 23 QRR were significantly different. These results coincide with the Aras et al. (2018) finding. There were differences in grouping, patients' selection and the measurement timings [37]. However, the number of subjects, the TM protocol were same. Aras et al. (2018), investigated 32 subjects with Class I malocclusion having crowding level 4-10mm and QRR compared between SLB and CB in CBCT [37]. Nine months after FOT they found higher incidence of slanted QRR with the CB system [37]. Current study also found differences in QRR in $\mathrm{CB}$ and the changes investigated after FOT.

The effectiveness of LE/P using the TM, TI and different phenotype factors of EET were observed on the maxillary anterior tooth QRR, and LE/P was applied at 4 weeks of intervals which is common protocol to call FOT patient in a regular interval for activation/adjustment.

Current study showed in comparison to TI (LE/P vs non-LE/P), 11, 13 and 23 QRR were significantly different. Furthermore, in 4 different TI group showed significant difference in QRR. LE/P+SLB showed significant differences in QRR of 11 (vs LE/P+CB and non- $\mathrm{LE} / \mathrm{P}+\mathrm{CB}$ ), 13 (vs non-LE/P+CB) and 23 (with all groups). Based on the results $\mathrm{LE} / \mathrm{P}+\mathrm{SLB}$ reflects the superiority in the QRR outcome. However, these aftereffects are incomparable as till to date no research has been explored the QRR association with LE/P vs non-LE/P in FOT and $\mathrm{LE} / \mathrm{P}+\mathrm{SLB}$ vs non- $\mathrm{LE} / \mathrm{P}+\mathrm{SLB}$ vs $\mathrm{LE} / \mathrm{P}+\mathrm{CB}$ vs non- $\mathrm{LE} / \mathrm{P}+\mathrm{CB}$. Ng et al., 2017 and Khaw et al., 2018, investigated RR after LE/P after effect on extracted premolars $(38,39)$. Ng et al., (2017) found LE/P has better outcome in RR compared to control (39). Moreover, Khaw et al., (2018) investigated the effect of LE/P on the healing of RR on extracted teeth and an excellent outcome has been observed [38]. 
The outcome of QRR in two different phenotype factors of EET were insignificant. Unilateral right or left and bilateral EET and buccally, occlusal and palatally placed EET has insignificant changes in QRR outcome. Brusveen et al. (2012), investigated QRR outcome using intra-oral radiographs of before and after FOT in unilateral EET vs control and found insignificant changes [30]. In a different protocol Lempesi et al. (2014) compared the outcome of QRR in 24 unilateral/bilateral EET vs 24 controls found no differences [40].

RR is quite common in FOT. Several TI and TM were investigated by researcher to lessen the RR [41]. Genetics, phenotype, geomorphometry and type of TI and TM may play important role in the outcome of RR [41,42]. This first-in-human study in Saudi population in relation to $2 \mathrm{TI}$ and 2+4 TM and in different phenotype factors of EET after FOT explored the amount QRR. This study was a prospective study and used CBCT for QRR outcome measurements with appropriate sample size however, investigation with more sample can give certainly better outcome. As well as this study is single center based, multiple center-based study might explore more certain conclusion. Knowing to what extent of EET patient after FOT are associated with QRR before starting any TI and TM, and being able to discuss such information with the patient, parents, and guardians, allows the choice of the most suitable FOT. Lastly, in a future investigation after long term follow-up in retention phase and relapse level might give different results in the outcome of QRR measurements.

\section{Conclusions}

QRR on CBCT in EET patients after FOT with SLB, LE/P, and LE/P+SLB showed superior outcome. It is difficult to affirm superiority of one TM or TI over the other only considering QRR amount which affirms more research utilizing similar protocol in different centre to identify possible similarities and disparities to accept the TM and TI.

Based on results -

Objectives 1 - in two treatment modalities (TM) [SLB vs CB] - significant disparities are found, SLB having superior outcome measure of QRR after FOT.

Objectives 2 - in two treatment intervention (TI) [LE/P vs non-LE/P] - significant disparities are found, LE/P having superior outcome measure of QRR after FOT.

Objectives 3 - in four different TI (LE/P+SLB, LE/P+CB, non-LE/P+SLB, and non-LE/P+CB) - significant disparities are found, LE/P+SLB having superior outcome measure of QRR after FOT.

Objectives 4 and 5 - in three different phenotypes of EET (Unilateral 13, Unilateral 23 and Bilateral) and positions of EET (Buccal, Occlusal and Palatal) - insignificant disparities were observed.

Author Contributions: "Conceptualization, MKA, KKG, AAF, SMM, KCS, PKC, HAH, HJA and RA; methodology, MKA, KKG; software, MKA, KKG; validation, MKA, KKG; formal analysis, MKA, KKG, AAF and PKC; investigation, MKA, KKG; resources, MKA, KKG, AAF and PKC; data curation, MKA, KKG; writing-original draft preparation, MKA, KKG; writing-review and editing, MKA, KKG, AAF, SMM, KCS, PKC, HAH, HJA and RA; funding acquisition, MKA. All authors have read and agreed to the published version of the manuscript."

Funding: The authors extend their appreciation to the Deanship of Scientific Research at Jouf University for funding this work through research grant no. (DSR-2021-01-0207).

Institutional Review Board Statement: After obtaining the approval from the Ethical Committee of Jouf University (LCBE\#4-22-2/40), which complies with the Declaration of Helsinki. Strengthening the Reporting of Observational Studies in Epidemiology (STROBE) guidelines are followed to design and conduct the study.

Informed Consent Statement: a written informed consent was obtained from all the subjects (one of the parents, either father and/or mother or legal guardian for adolescent subjects). 
Data Availability Statement: The data used to support the findings of this study are included in the article.

Acknowledgments: The authors extend their appreciation to the Deanship of Scientific Research at Jouf University for funding this work through research grant no. (DSR-2021-01-0207).

Conflicts of Interest: "The authors declare no conflict of interest."

\section{References}

1. Bishara SE, Saunders W. Textbook of Orthodontics: Saunders Book Company. Philadelphia, USA. 2001. ISBN 0721682898.

2. Ackerman MB. Enhancement Orthodontics: Theory and practice: Wiley-Blackwell. Ames, Iowa, USA. 2017. ISBN: 978-0-813-82623-3.

3. Talic NF. Adverse effects of orthodontic treatment: a clinical perspective. Saudi Dent J. 2011;23(2):55-59.

4. Storey E. The nature of tooth movement. Am J Orthod. 1973;63(3):292-314.

5. Mohammed AH, Tatakis DN, Dziak R. Leukotrienes in orthodontic tooth movement. Am J Orthod Dentofacial Orthop. 1989;95(3):231-237.

6. Proffit W, Fields Jr H, Sarver D. Orthodontic treatment planning: from problem list to specific plan. Contemporary Orthod. 2nd ed. North Carolina, Mosby. 1992;186-224.

7. Sarver D, Proffit W, Ackerman J. Diagnosis and treatment planning in orthodontics. Orthodontics, current principles and techniques. 3rd ed. St Louis: Mosby. 2000;27:128.

8. Parkin N, Benson PE, Thind B, Shah A, Khalil I, Ghafoor S. Open versus closed surgical exposure of canine teeth that are displaced in the roof of the mouth. Cochrane Database of Systematic Reviews 2017;8:CD006966.

9. Levander E, Bajka R, Malmgren O. Early radiographic diagnosis of apical root resorption during orthodontic treatment: a study of maxillary incisors. Eur J Orthod. 1998;20(1):57-63.

10. Brezniak N, Wasserstein A. Orthodontically induced inflammatory root resorption. Part I: the basic science aspects. Angle orthod. 2002;72(2):175-179.

11. Kurol J, Owman-Moll P, Lundgren D. Time-related root resorption after application of acontrolled continuous orthodontic force. Am J Orthod Dentofacial Orthop. 1996;110(3):303-310.

12. Qamruddin I, Alam MK, Khamis MF, Husein A. Minimally Invasive Techniques to Accelerate the Orthodontic Tooth Movement: A Systematic Review of Animal Studies. BioMed Research International, 2015 (2015), Article ID 608530, 10 pages. http://dx.doi.org/10.1155/2015/608530

13. Qamruddin I, Alam MK, Mahroof V, Fida M, Khamis MF, Husein A. Effects of low-level laser irradiation on the rate of orthodontic tooth movement and associated pain with self-ligating brackets. Am J Orthod Dentofacial Orthop. 2017;152:622-30

14. Qamruddin I, Alam MK. Low-Level Laser Therapy: History, Mechanisms and Medical Uses. Chapter 9. The Role of Low-Level Laser Therapy in Orthodontics (pp. 139-160). Nova Publisher. NY, USA. 2018. ISBN: 978-1-53613-226-7 eBook ISBN: 978-1-53613-124-6

15. Qamruddin I, Alam MK, Mahroof V, Fida M, Khamis MF, Husein A. Photobiostimulatory Effect of a Single Dose of Low-Level Laser on Orthodontic Tooth Movement and Pain. Pain Res Manag. 2021 May 10;2021:6690542. doi: $10.1155 / 2021 / 6690542$.

16. Alam MK. Laser assisted orthodontic tooth movement in saudi population: A randomized clinical trial. Bangladesh J Med Sci. 2019A;18(2):385-390.

17. Qamruddin I, Alam MK, Fida M, Khan AG. Effect of a single dose of low-level laser therapy on spontaneous and chewing pain caused by elastomeric separators. Am J Orthod Dentofacial Orthop. 2016;149(1):62-66.

18. Qamruddin I, Alam MK, Abdullah H, Kamran MA, Jawaid N, Mahroof V. Effects of single-dose, low-level laser therapy on pain associated with the initial stage of fixed orthodontic treatment: A randomized clinical trial. Korean J Orthod. 2018;48(2):90-97.

19. Alam MK. Laser-Assisted Orthodontic Tooth Movement in Saudi Population: A Prospective Clinical Intervention of Low-Level Laser Therapy in the 1st Week of Pain Perception in Four Treatment Modalities. Pain Res Management. $2019 B$. vol. 2019, Article ID 6271835, 11 pages. https://doi.org/10.1155/2019/6271835.

20. Khatri KK, Alam MK, Qamruddin I, Husein A. Effects of Low Level Laser Therapy on Gingival and Periodontal Tissues in Orthodontic Patients. Int J Orthod. 2019;30(2):21-27.

21. Jawad MM, Husein A, Azlina A, Alam MK, Hassan R, Shaari R. Effect of 940nm low level laser therapy on osteogenesis in vitro. J Biomed Optics. 2013;18 (12):128001.

22. Jawad MM, Husein A, Alam MK, Hassan R, Shaari R. Overview of non invasive Factors (low level laser and low intensity pulsed ultrasound) accelerating tooth movement during orthodontic treatment. Lasers Med Sci. 2014 Jan;29(1):367-72.

23. Jawad MM, Husein A, Alam MK, Hassan R, Shaari R, Azlina A, Salzihan MS. Effect of low level laser and low intensity pulsed ultrasound therapy on bone remodeling during orthodontic tooth movement in rats. Progress Orthod. 2018;19:10. 
24. Jawad MM, Husein A, Alam MK, Hassan R, Shaari R, Azlina A, Salzihan MS. Effect of 940nm Low Level Laser Therapy on Bone Remodelling During Orthodontic Tooth Movement in Rats. Journal of International Dental and Medical Research. 2019;12(3): 886-893.

25. Li Y, Deng S, Mei L, Li Z, Zhang X, Yang C, Li Y. Prevalence and severity of apical root resorption during orthodontic treatment with clear aligners and fixed appliances: a cone beam computed tomography study. Prog Orthod. 2020;Jan 6;21(1):1. doi: 10.1186/s40510-019-0301-1.

26. Patel S, Ford TP. Is the resorption external or internal? Dental Update. 2007;34(4), 218-229.

27. Bille M, Kvetny M, Kjaer I. A possible association between early apical resorption of primary teeth and ectodermal characteristics of the permanent dentition. Eur J Orthod. 2008;30(4):346-351.

28. Brin I, Tulloch JC, Koroluk L, Philips C. External apical root resorption in Class II malocclusion: a retrospective review of 1-versus 2-phase treatment. Am J Orthod Dentofacial Orthop. 2003;124(2):151-156.

29. Brezniak N, Goren S, Zoizner R, Dinbar A, Arad A, Wasserstein A, Heller M. A comparison of three methods to accurately measure root length. Angle Orthod. 2004;74(6):786-791.

30. Brusveen EM, Brudvik P, Bøe OE, Mavragani M. Apical root resorption of incisors after orthodontic treatment of impacted maxillary canines: a radiographic study. Am J Orthod Dentofacial Orthop. 2012 Apr;141(4):427-35. doi: 10.1016/j.ajodo.2011.10.022.

31. Alqerban A, Jacobs R, Souza PC, Willems G. In-vitro comparison of 2 cone-beam computed tomography systems and panoramic imaging for detecting simulated canine impaction-induced external root resorption in maxillary lateral incisors. Am J Orthod Dentofacial Orthop. 2009;136(6):764. e761-764. e711.

32. Sherrard JF, Rossouw PE, Benson BW, Carrillo R, Buschang PH. Accuracy and reliability of tooth and root lengths measured on cone-beam computed tomographs. Am J Orthod Dentofacial Orthop. 2010;137(4):100-108.

33. Leite V, Conti AC, Navarro R, Almeida M, Oltramari-Navarro P, Almeida R. Comparison of root resorption between self-ligating and conventional preadjusted brackets using cone beam computed tomography. Angle Orthod. 2012;82(6):1078-1082.

34. Malmgren O, Goldson L, Hill C, Orwin A, Petrini L, Lundberg M. Root resorption after orthodontic treatment of traumatized teeth. Am J Orthod. 1982;82(6):487-491.

35. Pandis N, Nasika M, Polychronopoulou A, Eliades T. External apical root resorption in patients treated with conventional and self-ligating brackets. Am J Orthod Dentofacial Orthop. 2008;134(5):646-651.

36. Chen SSH, Greenlee GM, Kim JE, Smith CL, Huang GJ. Systematic review of self-ligating brackets. Am J Orthod Dentofacial Orthop. 2010;137(6):721-726.

37. Aras I, Unal I, Huniler G, Aras A. Root resorption due to orthodontic treatment using self-ligating and conventional brackets: A cone-beam computed tomography study. J Orofac Orthop. 2018 May;79(3):181-190. English. doi: 10.1007/s00056-018-0133-5.

38. Khaw CMA, Dalci O, Foley M, Petocz P, Darendeliler MA, Papadopoulou AK. Physical properties of root cementum: Part 27. Effect of low-level laser therapy on the repair of orthodontically induced inflammatory root resorption: A double-blind, split-mouth, randomized controlled clinical trial. Am J Orthod Dentofacial Orthop. 2018;154(3):326-336.

39. Ng D, Chan AK, Papadopoulou AK, Dalci O, Petocz P, Darendeliler MA. The effect of low-level laser therapy on orthodontically induced root resorption: a pilot double blind randomized controlled trial. Eur J Orthod. 2017;40(3):317-325.

40. Lempesi E, Pandis N, Fleming PS, Mavragani M. A comparison of apical root resorption after orthodontic treatment with surgical exposure and traction of maxillary impacted canines versus that without impactions. Eur J Orthod. 2014 Dec;36(6):690-697.

41. Janson GR, de Luca Canto G, Martins DR, Henriques JFC, de Freitas MR. A radiographic comparison of apical root resorption after orthodontic treatment with 3 different fixed appliance techniques. Am J Orthod Dentofacial Orthop. 2000;118(3):262-273.

42. Jiang RP, McDonald J, Fu MK. Root resorption before and after orthodontic treatment: a clinical study of contributory factors. Eur J Orthod. 2010;32(6):693-697. 